\title{
Desert Takeover?
}

\author{
Jack Trevors • Milton Saier
}

Published online: 11 January 2008

(C) Springer Science + Business Media B.V. 2007

In July, 2007, the U.N. released a 78 page report summarizing studies conducted by 200 experts from 25 nations concerning desertification and its threat to global, social and ecological stability. The study concluded that people displaced by desertification put tremendous strain on the resources of the countries to which they migrate. They also put stress on social structures and threaten international stability. Zafaar Adeel, the study's lead author and head of the U.N. University's International Network on Water, Environment and Health, noted that there can be a chain reaction leading to social turmoil. The report recommended several ways to slow the advance of deserts, such as plantings crops and forests in drylands adjacent to advancing deserts.

Desertification is estimated to already affect at least 100 to 200 million people while threatening the lives and welfare of a much larger number. The largest area where desertification is occurring is sub-Saharan Africa. People there are moving to Northern Africa and Europe.

\footnotetext{
M. Saier $(\bowtie)$

Division of Biological Sciences (0116),

University of California, San Diego,

La Jolla, CA 92093-0116, USA

e-mail: saier@biomail.ucsd.edu

J. Trevors

Department of Environmental Biology,

University of Guelph,

Rm 3220 Bovey Bldg,

Guelph, ON, N1G 2W1, Canada
}

The second most important area includes the former Soviet republics in central Asia. Desertification causes conflict as has occurred in Sudan's Darfur region. In this region alone, international experts believe that about 200,000 people have died and 2.5 million have been driven from their homes in the last four years of strife resulting from displacement, bitter poverty and resource insufficiency.

What does the report recommend to counteract desertification? First of all, it suggests improving both the nature and quality of crop and forest plantings as mentioned above. These drylands encompass more than $40 \%$ of the world's land. Such actions would not only slow desertification, it would also provide resources to help fight global warming. The report suggests that carbon markets would create financial mechanisms to encourage the planting of vegetation in drylands, renewing depleted resources. Among current efforts, China, recognizing the threat of desertification, is planting a $700 \mathrm{~km}$ "Great Green Wall" of trees and grasslands to slow the advance of deserts. Algeria is also putting up a "green wall" against the Sahara. In these efforts, it is important to recognize the essentiality of planting drought resistant shrubs and trees that can withstand adverse conditions.

Eco-restoration and eco-tourism might create jobs to desert regions, encouraging people to stay. Fish farms represent another option for the use of these areas. Countries including Israel, Pakistan and Egypt have successfully established such farms in drylands and 
deserts. Thus, many means have been devised to slow and even reverse the devastating effects of desertification. But will they be sufficient to counter the ecodestruction in other areas such as Brazil and Indonesia where rain forests are being destroyed at appalling rates? And even in areas where planting is underway, will these efforts prove successful?

Let's hope the short term successes recorded to date will continue as new ecosystems become established and self-sustaining. What measures can be implemented to expand such efforts? Full recognition of the magni- tude of the problem is first of all required, and secondly, huge, expensive programs must be implemented; only then can we expect to reap benefits. Just imagine the deserts in retreat!

Still, all will be for naught if the world's human population continues to grow. Starving people can't be worrying about the future state of our planet. Their concerns relate to the here and now. Yet a good planet is hard to find. We'd better be careful with this one and treat it right! And treating it right means controlling and reversing the damage we have already done. 